\title{
Electro and Echocardiographic Profile of Young American Navy Recruits Presented with Syncope
}

\author{
Nadeem AUR ${ }^{1,2^{*}}$, Matthew $\mathbf{S}^{2}$, Molnar $\mathrm{J}^{2}$, Chaudhary $\mathbf{S} \mathbf{A}^{1,2}$, Al-Khafaji $\mathrm{K}^{1,2}$, Jahangir $\mathrm{TR}^{3}$, Nadeem $\mathbf{R}^{2}$, Mirza $\mathbf{M}^{1,2}$ and $\mathbf{S h a f e r}^{1,2}$ \\ ${ }^{1}$ Captain James A. Lovell Federal Healthcare Center, 3001 Green Bay Rd, North Chicago, IL, USA \\ ${ }^{2}$ Rosalind Franklin University of Medicine and Science, 3333 Green Bay Road, North Chicago, IL, USA \\ ${ }^{3}$ Kaiser Permanente Hospital South, Adult Primary Care-Unit C, 6600 Bruceville Road, Sacramento, CA, USA
}

"Corresponding author: Nadeem AUR, MD, FCCP, Captain James A. Lovell Federal Healthcare Center, 3001 Green Bay Rd, North Chicago, IL 60064, USA, Tel: +224 610-1525, E-mail: Aminnadeem@yahoo.com

Received: November 19, 2018; Accepted: December 06, 2018; Published: December 11, 2018

Copyright: (c) 2018 Nadeem AUR, et al. This is an open-access article distributed under the terms of the creative commons attribution license, which permits unrestricted use, distribution, and reproduction in any medium, provided the original author and source are credited.

\begin{abstract}
Background: The etiology of syncope in young adults is poorly defined and most studies reveal benign etiologies. However, case reports suggest that exercise-related syncope, even in young patients, can be a harbinger of sudden cardiac death. We aim to determine the characteristics of young adults presenting with syncope in a diverse population of navy recruits.
\end{abstract}

Methods: A retrospective chart review was performed on all Navy recruits who presented with a complaint of syncope to the Captain James A. Lovell Federal Health Care Center (JALFHCC) between June 1, 2006 and May 31, 2013. There was a total of 154 charts. Demographics and clinical data, along with Electrocardiogram (EKG), telemetry, and echocardiographic findings were recorded. Variables were compared between the subjects with abnormal cardiac profile and subjects with normal cardiac results.

Results: The sample size of 154 included 95 males and 59 females. There were $13(8.4 \%)$ subjects who were found to have concerned cardiac findings; 9 were males ( $9.5 \%$ of males) and 4 were females ( $6.8 \%$ of females). Compared to those without cardiac findings, there were no significant differences in age $(20.2 \pm 3.8$ vs. $20.2 \pm 2.5$ years), body mass index ( $25.8 \pm 2.8$ vs. $24.7 \pm 3.5)$, prior history of syncope ( 23 vs. $21 \%$ ), or presence of exertional syncope (77 vs. $63 \%)$.

Conclusion: A significant proportion of young American navy recruits have evidence of concerning electro and echocardiographic findings. We did not find any clinical profile predicting such findings although there was a statistically insignificant, but noticeable trend towards exertional syncope in those who had concerning cardiac abnormalities.

Keywords: Syncope; Navy recruits; Electro and echocardiographic findings

\section{Introduction}

Syncope is a prevalent medical condition that accounts for $3.5 \%$ of all emergency room visits and 1 to $6 \%$ of all hospital admissions annually in the United States [1]. Syncope is defined as a sudden and temporary loss of consciousness associated with concurrent loss of postural tone secondary to a reduction of cerebral blood flow followed by restoration to a normal physiological state [2]. Since the subjects of syncope often cannot recall the events leading to their altered mental state, the etiology of syncope in the young and elderly remains a diagnostic challenge and the source of ongoing research [3].

Syncope can occur in any age group although the elderly usually undergoes more extensive diagnostic evaluation as the likelihood for finding cardiac pathology is higher and they have more documented comorbid disease $[4,5]$. Conversely, the etiologies of syncope in the young remain poorly characterized with most of the literature focusing on benign conditions such as psychiatric and neuro-cardiogenic causes [2,4-8]. Ganzeboom et al. elucidated the different triggers of syncope in 394 medical students of both genders and discovered that a warm environment, prolonged standing, pain, illness, and alcohol represent some of the triggers for syncope [9]. More importantly, O'Connor et al. have also reported exertion-related syncope in young athletes with and without history of cardiac disease leading to sudden cardiac death [7]. These findings may suggest that syncope, most commonly exertional in nature, may not be limited to benign causes in the young population especially amongst patients with underlying heart conditions such as hypertrophic cardiomyopathy and a history of strenuous exercise.

Nearly $60 \%$ of syncope cases that interfere with activities of daily living in the young require adequate study $[10,11]$. We studied young American navy recruits who presented in the inpatient or outpatient settings. This group of subjects was thought to be ideal as they are trained for jobs requiring a high level of physical fitness. Also, the nature of their occupation mandates a standard of frequent detailed objective evaluation.

\section{Methods}

The study is a retrospective chart review examining navy recruits and students who presented to Captain James A. Lovell Federal Health 
Page 2 of 4

Care Center [JALFHCC] with syncope between June 1, 2006 and May 31, 2013. Our health care facility is a teaching hospital affiliated with Rosalind Franklin University of Medicine and Science. It serves veterans, navy recruits, navy students, active duty navy personnel and their dependents. The protocol was approved by our Institutional Review Board. Patients who satisfied inclusion criteria were enrolled from the computerized patient record system termed [CPRS]. For inclusion, syncope was defined as a transient loss of consciousness which was acute and abrupt in onset and followed by complete recovery. Patients were excluded if they were younger than 18 years of age or noted to have any of the following; prolonged episode of confusion [ $>10$ minutes] following the episode, witnessed tonic-clonic activity that led to diagnosis of seizure disorder by neurology, presence of bowel or bladder incontinence or both, presence of tongue biting, or presence of trauma. Patients with syncope including both exertional and non-exertional syncope were evaluated by conventional diagnostic tests; Electrocardiogram [EKG], cardiac monitoring on telemetry as achieved by admission to the hospital, Echocardiogram, and further work up as determined to be clinically indicated by the attending clinician and/or associated consult services.

Demographic data was recorded including age, race, gender, body mass index $[\mathrm{BMI}]$, prior history of syncope, exertional vs. nonexertional nature, and prior history of syncope. Patients were categorized into two groups; concerning cardiac findings and nonconcerning cardiac findings based on a cardiac evaluation by a consulting cardiologist. Variables of these 2 groups were compared.

\section{Statistical Analysis}

Statistical analysis was performed on IBM SPSS Statistical program [version 22, IBM Corporation, Pittsburgh, PA]. Statistical analysis consisted of computation of means and standard deviations for continuous variables and frequencies for categorical variables. Differences in continuous variables between the two study groups were analyzed by independent sample $t$ test. Differences in categorical variables were analyzed by chi-square test or Fisher's exact tests as appropriate. A two-sided alpha error of $\mathrm{p} \leq 0.05$ was considered statistically significant.

\section{Results}

Over the 7-year period, 150 navy recruits and 4 students met the inclusion criteria. The mean age was $20.2 \pm 2.62$ years. There were more males (95) than females (59); males were significantly taller and had greater body weight than females. More females had prior history of syncope $(30.5 \%)$ than males $(15.8 \%)$, There were no statistically significant differences between genders in age, BMI, and presence of exertional syncope (Table 1 ).

\begin{tabular}{|c|c|c|c|c|}
\hline \multicolumn{2}{|c|}{ Variables } & Overall & Male & Female \\
\hline \multicolumn{2}{|c|}{ Number } & 154 & 95 & 59 \\
\hline \multirow{4}{*}{ Race } & Caucasian & $89(58 \%)$ & 59 & 30 \\
\hline & $\begin{array}{l}\text { African } \\
\text { American }\end{array}$ & $54(35 \%)$ & 29 & 25 \\
\hline & Hispanics & $3(2 \%)$ & 0 & 3 \\
\hline & Other & $8(5 \%)$ & 7 & 1 \\
\hline \multicolumn{2}{|c|}{ Weight (Ibs.) } & $163.5 \pm 32$ & $176 \pm 31$ & $144 \pm 23^{* *}$ \\
\hline
\end{tabular}

\begin{tabular}{|l|l|l|l|}
\hline Height (inches) & $68 \pm 4$ & $70 \pm 3$ & $64 \pm 2.6^{\star *}$ \\
\hline BMI & $24.8 \pm 3.5$ & $25 \pm 3.6$ & $24.4 \pm 3.2$ \\
\hline Prior history of syncope & $33(21 \%)$ & $15(15.8 \%)$ & $18(30.5 \%)^{\star}$ \\
\hline Exertional syncope & $99(64 \%)$ & $61(64 \%)$ & $38(64 \%)$ \\
\hline
\end{tabular}

${ }^{*} p<0.05$; males versus females, ${ }^{* *} p<0.001$; males versus females, BMl; Body Mass Index

Table 1: Demographics of subjects presented with syncope.

\begin{tabular}{|l|l|l|}
\hline Variables & $\begin{array}{l}\text { Cardiac } \\
\text { abnormality } \\
\mathbf{( N = 1 3 )}\end{array}$ & $\begin{array}{l}\text { No cardiac } \\
\text { abnormality } \\
(\mathbf{N}=141)\end{array}$ \\
\hline Age & $20.2 \pm 3.8$ & $20.2 \pm 2.5$ \\
\hline Height (inches) & $69.7 \pm 5.4$ & $67.9 \pm 3.9$ \\
\hline Weight (Ibs.) & $180 \pm 39^{*}$ & $162 \pm 31$ \\
\hline BMl & $25.8 \pm 2.8$ & $24.7 \pm 3.5$ \\
\hline Prior history of syncope & $3(23 \%)$ & $30(21 \%)$ \\
\hline Exertional syncope & $10(77 \%)$ & $89(63 \%)$ \\
\hline Not exertional syncope & $3(23 \%)$ & $52(37 \%)$ \\
\hline $\begin{array}{l}* \\
\text { abno }<05 ; \text { subjects with cardiac abnormality versus subjects with no cardiac }\end{array}$ \\
\hline
\end{tabular}

Table 2: Demography of subjects with cardiac versus no cardiac abnormalities.

There were 13 subjects (8.4\%) who had concerning cardiac abnormalities. Characteristics of patients with concerning cardiac findings compared to those without concerning cardiac findings are summarized in Table 2. Subjects with concerning cardiac findings had greater body weight with no significant differences in age, height or BMI. The details of patient characteristics and concerning cardiac abnormalities are listed for each of the 13 subjects in Table 3 . There was a trend toward more exertional syncope in those who had concerning cardiac abnormalities.

\section{Discussion}

We find a trend suggesting patients with exertional syncope tended to have concerning cardiac findings that included early repolarization and RBBB, hyperdynamic LV function, mildly dilated right ventricle, sinus bradycardia, right axis deviation, right ventricular hypertrophy, left posterior fascicular block, Atrial Fibrillation, prolonged QT interval, tricuspid regurgitation, mitral regurgitation, pulmonary regurgitation, WPW, LBBB, junctional rhythm, and sinus pauses. Though this trend did not reach a statistically significant level. Da Costa et al. studied 329 patients with syncope who underwent electrophysiology study [EPS] and found that ECG abnormality was the only predictive variable associated with a significant arrhythmic event in patients with episode of syncope and a negative EPS [11].

Syncope cannot be ignored particularly in subjects employed in jobs which are high-risk and physically demanding activities for e.g. pilots, drivers, machine operators, and military personnel. Evaluation of such patients can be very costly; therefore, risk stratification and case 
selection are crucial to provide cost effective management. Clinical history can be helpful in selecting those young adult subjects for further evaluation who have syncope during exercise or who have a family history of syncope, sudden death, myocardial disease, or arrhythmias [11].

In our study we compared subjects with concerning cardiac findings to those without concerning cardiac findings and noted no statistically significant differences in age, BMI, prior history of syncope, or exertional syncope. Although we do acknowledge the sample size as being possibly inadequate to detect such an effect if one exists.

\begin{tabular}{|c|c|c|c|c|c|}
\hline $\begin{array}{l}\text { Serial } \\
\text { No. }\end{array}$ & $\begin{array}{l}\text { Age } \\
\text { (Years) }\end{array}$ & Gender & Race & $\begin{array}{l}\text { Type of } \\
\text { Syncope }\end{array}$ & $\begin{array}{l}\text { Concerning } \\
\text { Cardiac } \\
\text { Abnormalities }\end{array}$ \\
\hline 1 & 18 & Male & $\begin{array}{l}\text { African } \\
\text { American }\end{array}$ & Exertional & $\begin{array}{l}\text { Early repolarization } \\
\text { and } \text { RBBB }^{*}\end{array}$ \\
\hline 2 & 20 & Male & Caucasian & At rest & $\begin{array}{l}\text { Early repolarization*, } \\
\text { hyperdynamic LV } \\
\text { function, and mildly } \\
\text { dilated } \\
\text { ventricle }^{* *}\end{array}$ \\
\hline 3 & 18 & Female & Caucasian & Exertional & $\begin{array}{l}\text { Mild right atrial and } \\
\text { ventricular } \\
\text { enlargement }^{* *}\end{array}$ \\
\hline 4 & 23 & Male & Caucasian & Exertional & $\begin{array}{l}\text { Sinus bradycardia, } \\
\text { right axis deviation, } \\
\text { right ventricular } \\
\text { hypertrophy, and left } \\
\text { posterior fascicular } \\
\text { block }^{*}\end{array}$ \\
\hline 5 & 18 & Female & Caucasian & Exertional & Atrial Fibrillation*** \\
\hline 6 & 32 & Male & $\begin{array}{l}\text { African } \\
\text { American }\end{array}$ & Exertional & $\begin{array}{l}\text { WPW and sinus } \\
\text { arrhythmia }{ }^{* * *}\end{array}$ \\
\hline 7 & 19 & Male & $\begin{array}{l}\text { African } \\
\text { American }\end{array}$ & At rest & $\begin{array}{l}\text { Right ventricular } \\
\text { hypertrophy and } \\
\text { RBBB* }^{*}\end{array}$ \\
\hline 8 & 20 & Female & Caucasian & Exertional & $\begin{array}{l}\text { Hyperdynamic LV } \\
\text { function, dilated right } \\
\text { ventricle, and } \\
\text { tricuspid } \\
\text { regurgitation** }\end{array}$ \\
\hline 9 & 19 & Male & Caucasian & Exertional & $\begin{array}{l}\text { Estimated LVEF is } \\
40-45 \% \text { with mild } \\
\text { global hypokinesia** }\end{array}$ \\
\hline 10 & 18 & Female & Caucasian & Exertional & $\begin{array}{l}\text { Prolonged } \\
\text { interval***, } \\
\text { regurgitation, mitral } \\
\text { regurgitation, and } \\
\text { pulmonary } \\
\text { regurgitation }{ }^{* *}\end{array}$ \\
\hline 11 & 20 & Male & Caucasian & Exertional & Sinus pauses ${ }^{\star * *}$ \\
\hline 12 & 18 & Male & $\begin{array}{l}\text { African } \\
\text { American }\end{array}$ & Exertional & $\begin{array}{l}\text { LBBB, junctional } \\
\text { rhythm, early } \\
\text { repolarization, and } \\
\text { sinus bradycardia**** }\end{array}$ \\
\hline 13 & 19 & Male & Caucasian & At rest & WPW* \\
\hline
\end{tabular}

LBBB: Left bundle branch block, LV: Left ventricle, LVEF; Left ventricular ejection fraction, RBBB: Right bundle branch block, WPW: Wolf Parkinson White syndrome, * Electrocardiogram Findings, ${ }^{* *}$ Echocardiographic findings, ${ }^{* * *}$ Electrocardiographic and Cardiac Monitor Findings

Table 3: Subjects with concerning cardiac abnormalities.

One of the strengths of our study was all patients who presented with syncope were evaluated for arrhythmic disorders and structural heart disease. The occurrence of concerning cardiac findings, however, did not necessarily specify that syncope was caused by a cardiovascular disorder. We acknowledge several weaknesses in our study. The sample size was underpowered. The arrhythmias or structural heart diseases that were detected may not have a causal or contributory relationship with the syncopal event although there was no evidence to the contrary either. The diagnostic evaluation performed may have been more rigorous owing to the nature of subjects' duties, so results can only be generalized to the population at large with caution. Other limitations include a lack of data on cardiac assessments done prior to enrolling in the navy. Of note the nature of a single-center study design prohibits the generalizability of results. Also, of note our study examines the relationship of syncope with cardiac etiologies in young adult subjects. Further studies on this clinical question are warranted to enable correlation between such cardiac findings and significant mortality and morbidity in the context of syncopal events.

\section{Conclusion}

A significant proportion of young American navy recruits have evidence of concerning electro and echocardiographic findings. The clinical profile of young subjects presenting with syncope is variable. Although there was a statistically insignificant, but noticeable trend towards exertional syncope in those who had concerning cardiac abnormalities. Larger-scale studies are necessary to reflect the reproducibility of these results.

\section{Conflicts of Interest}

There are no conflicts of interest for the present study.

\section{References}

1. Day SC, Cook EF, Funkenstein H, Goldman L (1982) Evaluation and outcome of emergency room patients with transient loss of consciousness. Am J Med 73: 15-23.

2. Colivicchi F, Ammirati F, Santini M (2004) Epidemiology and prognostic implications of syncope in young competing athletes. Eur Heart J 25: 1749-1753.

3. Kapoor WN, Karpf M, Maher Y, Miller RA, Levey GS (1982) Syncope of unknown origin: The need for a more cost-effective approach to its diagnostic evaluation. JAMA 247: 2687-2691.

4. Lipsitz LA, Wei JY, Rowe JW (1985) Syncope in an elderly, institutionalised population: Prevalence, incidence, and associated risk. QJM: An International Journal of Medicine 55: 45-54.

5. Kapoor W, Snustad D, Peterson J, Wieand HS, Cha R, et al. (1986) Syncope in the elderly. Am J Med 80: 419-428.

6. Moya A, Sutton R, Ammirati F, Blanc JJ, Brignole M, et al. (2009) Guidelines: Guidelines for the diagnosis and management of syncope (version 2009): The Task Force for the Diagnosis and Management of Syncope of the European Society of Cardiology (ESC). Eur Heart J 30: 2631-2671.

7. O'Connor FG, Oriscello RG, Levine BD (1999) Exercise-related syncope in the young athlete: reassurance, restriction or referral?. Am Fam Physician 60: 2001-2008. 
Citation: Nadeem AUR, Matthew S, Molnar J, Chaudhary SA, Al-Khafaji K, et al. (2018) Electro and Echocardiographic Profile of Young American Navy Recruits Presented with Syncope. J Cardiovasc Dis Diagn 6: 350. doi:10.4172/2329-9517.1000350

Page 4 of 4

8. Costa DA, Gulian JL, Romeyer-Bouchard C, Messier M, Zarqane N, et al (2006) Clinical predictors of cardiac events in patients with isolated syncope and negative electrophysiologic study. Int J Cardiol 109: 28-33.

9. Ganzeboom KS, Colman N, Reitsma JB, Shen WK, Wieling W (2003) Prevalence and triggers of syncope in medical students. Am J Cardiol 91: 1006-1008.
10. Maron BJ, Mitten MJ, Quandt EF, Zipes DP (1998) Competitive athletes with cardiovascular disease-The case of Nicholas Knapp. N Engl J Med 339: 1632-1635.

11. Koenig D, Linzer M, Pontinen M, Divine GW (1992) Syncope in young adults: Evidence for a combined medical and psychiatric approach. J Intern Med 32: 169-176. 